\title{
Evaluation of the Effects of Alcohol on De-Emulsification of Niger Delta Crude Oil Using Commercial De-Emulsifiers
}

\author{
K. C. Igwilo' , S. T. A. Okolie' ${ }^{2}$, P. A. L. Anawe ${ }^{2}$, Ogbudu Roland ${ }^{3}$, Jude Odo ${ }^{1}$ \\ ${ }^{1}$ Federal University of Technology, Owerri, Nigeria \\ ${ }^{2}$ Covenant University, Ota, Nigeria \\ ${ }^{3}$ Chevron Oil and Gas Company, Lagos, Nigeria \\ Email: meetkevin2006@yahoo.com
}

How to cite this paper: Igwilo, K.C., Okolie, S.T.A., Anawe, P.A.L., Roland, O. and Odo, J. (2017) Evaluation of the Effects of Alcohol on De-Emulsification of Niger Delta Crude Oil Using Commercial De-Emulsifiers. Open Journal of Yangtze Gas and Oil, 2, 168-175.

https://doi.org/10.4236/ojogas.2017.23013

Received: April 6, 2017

Accepted: July 11, 2017

Published: July 14, 2017

Copyright $\odot 2017$ by authors and Scientific Research Publishing Inc. This work is licensed under the Creative Commons Attribution International License (CC BY 4.0).

http://creativecommons.org/licenses/by/4.0/

\begin{abstract}
This research work evaluates the effects of alcohol on de-emulsification of Niger Delta crude oil using RP6000 and Chimec 2439 as de-emulsifiers. The laboratory measurements were carried out as per API standard. Stable emulsion was prepared using brine. The samples were de-emulsified. Methanol and ethanol were added respectively, with water and without water as modifiers. The measurements of the effect of adding alcohols on water separation efficiency were carried out using methanol to water ratio, $M=4: 1$ and ethanol water ratio, $E=4: 1$. The results show that solubility with alcohol is greater in emulsion than the solubility of alcohol without water. Some comparisons were also made based on the plots on percent water separation versus time for the two modifiers and de-emulsifiers. The maximum separation efficiency of $61 \%$ was obtained at concentration of $25 \%$ methanol, 75\% RP6000, $20 \mathrm{ppm}$ and Chimec 2439 gave maximum separation efficiency of $56.6 \%$ at concentration of $75 \%, 20 \mathrm{ppm}$ at 120 minutes. Based on the results, methanol therefore gave larger effect on water separation efficiency than ethanol.
\end{abstract}

\section{Keywords}

De-Emulsification, Niger Delta Crude Oil, RP6000, Chimec 2439, Methanol, Ethanol, Separation Efficiency

\section{Introduction}

Emulsion is a heterogeneous system, containing at least immiscible liquid intimately dispersed in another in the form of droplets with a diameter, in general, ranging between $(0.1 \sim 20)$ microns, and it is stabilized by an emulsifying agent, 
asphaltenes, resins and finely divided solids. The dispersed droplets are known as the internal phase. The liquid surrounding the dispersed droplets is the external or continuous phase. The emulsifying agent separates the dispersed droplets from the continuous phase [1]. Water-in-oil emulsion is formed during the production of oil, which is often accompanied with water. The stability of the emulsion is ranging from a few minutes to years depending on the nature of the crude oil [2]. Crude oils consist of, in any case, a series of hydrocarbons such as alkenes, naphthenes, and aromatic compounds as well as phenols, carboxylic acids, and metals. A major fraction of sulfur and nitrogen compounds may be present as well. The carbon numbers of all these components range from 1 (methane) through 50 or more (asphaltenes). Some of these components (asphaltenes, resins, wax, and naphthenic acids) can form films at oil surfaces. So, the tendency to form stable or unstable emulsions of different kinds varies greatly among different oils [3]. The natural petroleum emulsion resulting from the secondary production consists of crude oil as dispersion medium and brine as dispersed phase, normally stabilized by natural chemicals such as asphaltenes, resins, and solids such as clays and waxes [2].

Emulsions are undesirable because the volume of dispersed water occupies space in the processing equipment and pipelines, increased operating and capital costs. Moreover, the characteristics and physical properties of oil change significantly on emulsification. Emulsion resolution is therefore an important element in handling the petroleum, from the time it is produced until it enters the refining process. In order to minimize the production problems related with crude oil emulsions and environmental concerns, petroleum operators need to prevent emulsion formation or to break it [4]. The treatment of water-in-crude oil emulsions involves the application of mechanical, thermal, electrical, and chemical processes [5]. Chemical method of resolving crude oil emulsions are based on the addition of reagents (de-emulsifiers) which destroy the protective action of hydrophobic emulsifying agents and allow the water droplets to coalesce. There are anionic, cationic and nonionic surfactants that have been used as de-emulsifiers [6]. Success of chemical de-emulsifying method is dependent upon the adequate quantity of a properly selected chemical that must be added into the emulsion, through mixing of the chemical with the emulsion, adequately heat may be required to facilitate or fully resolve an emulsion. De-emulsifiers permit agglomeration, coalescence and gravity settling of the water droplets [7]. The formulation of commercial de-emulsifiers is largely based on empirical approaches in an attempt to get the effective agent, which can work in shorter separation times and smaller dosages [6]. In the petroleum industry the usual emulsions encountered are water droplets dispersed in the oil phase and termed as water-in-oil emulsion (W/O), conversely, if the oil is the dispersed phase, it is termed oil-in-water $(\mathrm{O} / \mathrm{W})$ emulsion. In addition to the usual emulsion types, multiple emulsions for instance, water droplets dispersed in oil droplets that are in turn dispersed in a continuous water phase $(\mathrm{W} / \mathrm{O} / \mathrm{W})$ can occur.

Emulsion Stability is widely used to refer to the persistence of an emulsion in 
the environment, and has been identified as an important characteristic of water-in-oil emulsions. Some emulsions quickly decompose into separate oil and water phases once removed from the sea surface, while more stable emulsions can persist for days to years. Recent work indicates that the viscosity of an emulsion is related to its stability [8]. Crude oil is found in the reservoir in association with gas and saline formation water. The numbers of wells now co-producing water with crude oil is steadily increasing, these immiscible fluids are readily emulsified by the simultaneous action of pressure drop at the well head [9]. The knowledge of the properties and characteristics of the emulsion and the mechanisms that are taking place during coalescence of water droplets are required for fast separation [10].

De-emulsifiers are molecules that aid the separation of oil from water usually at low concentrations. They prevent formation of water in oil mixture. The structures of de-emulsifiers are not easily categorized as emulsifiers. Some de-emulsifiers are polymers; others have structures similar to non-ionic emulsifiers. De-emulsifiers are surfactants that are important in breaking the emulsion system [11].

The best de-emulsifiers are one that can reduce the interfacial shear viscosity increases the interfacial mobility and destabilizing the water-oil emulsion. To ensure the high quality performance, a de-emulsifier should possess the following characteristics [12]: 1) The de-emulsifier should be able to partition into the water phase and oil phase 2) Dissolved in the oil phase 3) The concentration of the de-emulsifier in the droplet must be sufficient to ensure a high enough diffusion flux to the interface.

The de-emulsifier must be high enough to suppress the interfacial tension gradient, thus accelerating the rate of film drainage hence promoting coalescence. Dodd [13] in 1954, concluded that the de-emulsifiers that are soluble in both phases are effective in breaking crude oil emulsions, provided that very small amounts of hydrochloric or Sulfuric acid are also added. He suggested the use of Phenol and Sulfuric acid. Hanapi [14] in 2006, investigated that the combination of oil soluble de-emulsifiers and water-soluble de-emulsifiers produced great result in water separation. He also observed that the formulation de-emulsifiers is better than other commercial de-emulsifier.

\section{Materials and Methodology}

The aim is to experimentally investigate the effect of de-emulsifier concentration, separation time and modifier agent to break crude oil emulsion. The main purpose of the research is to know the degree of the effectiveness of methanol and ethanol to emulsion de-emulsifiers. Two commercial de-emulsifiers were used: RP6000 and Chimec 2439. Chemical method was applied in breaking crude oil emulsion.

\subsection{Apparatus Used in Experiments}

The equipment used were: 
1) Water bath with temperature controller type (Haak-G and Haak-D)

2) Water bath type (Gerhardt Bonn EV2) connects with thermocouple.

3) Batch reactor with stirrer.

4) Electrical mixer with standard turbine impeller type (RL10 M 24684). The mixer calibrated using Dual Digital Tachometer (DT-2268) made in Germany.

5) Electronic balance type (Ntrols mod. Mark 2200) with \pm 0.05 g accuracy.

6) Clock timer.

7) Thermometer.

8) Cylinders (10 $\mathrm{ml})$ and Beakers $(100 \mathrm{ml})$.

9) Separator funnel.

10) Burette.

\subsection{Materials}

Table 1 below shows the Niger Delta crude oil sample. Their laboratory measurements were carried out and the physical properties as stated in the table were obtained. This is $28.6^{\circ}$ API crude oil with minimum salt, water and sediment contents of $0.0007 \%$ and $0.046 \%$ respectively. Asphaltene and sediments help to stabilized the emulsion during emulsification before being de-emulsified.

Table 1. Physical properties of the niger delta crude oil.

\begin{tabular}{cccccccc}
\hline $\begin{array}{c}\text { Sp. Gr. } \\
\text { at } 15.6^{\circ} \mathrm{C}\end{array}$ in API $\left({ }^{\circ} \mathrm{API}\right)$ & $\begin{array}{c}\text { Salt content Water and Sediment } \\
\text { content } / \% \text { vol. }\end{array}$ & $\begin{array}{c}\text { Asphaltene } \\
/ \% \text { wt. }\end{array}$ & $\begin{array}{c}\text { Ash content } \\
/ \% \text { wt. }\end{array}$ & $\begin{array}{c}\text { Sulfur content } \\
/ \% \text { wt. }\end{array}$ & $\begin{array}{c}\text { Viscosity } \\
\text { at } 20^{\circ} \mathrm{C}(\mathrm{cp})\end{array}$ \\
\hline 0.884 & 28.6 & 0.0007 & 0.046 & 2.24 & 0.0152 & 2 & 48 \\
\hline
\end{tabular}

The other materials that were used in experimental work are methanol and ethanol as shown in Table 2. Methanol and ethanol have $99.9 \%$ purity from different suppliers of their specific gravity 0.792 and 0.7180 respectively at $20^{\circ} \mathrm{C}$.

Table 2. Properties of chemical materials.

\begin{tabular}{ccccccc}
\hline Substance & Formula & $\begin{array}{c}\text { Molecular } \\
\text { Weight }\end{array}$ & $\begin{array}{c}\text { Specific } \\
\text { Gravity }\end{array}$ & $\begin{array}{c}\text { Melting } \\
\text { Point } /{ }^{\circ} \mathrm{C}\end{array}$ & Supplier & Purity $/ \%$ \\
\hline Methanol & $\mathrm{CH}_{3} \mathrm{OH}$ & 32.04 & 0.792 & - & B.D.H & 99.9 \\
Ethanol & $\mathrm{C}_{2} \mathrm{H}_{5} \mathrm{OH}$ & 46.069 & 0.7180 & - & G.C.C & 99.9 \\
\hline
\end{tabular}

Specific gravity at $20^{\circ} \mathrm{C}$.

\subsection{Chemical De-Emulsifiers Are}

1) RP6000 (commercial) and the chemical composition of this de-emulsifier is not known. The PERTROLITE Company adopted this de-emulsifier in desalting process in East Baghdad oil field.

2) Chimec 2439 (commercial), which is a blend of non-ionic oil soluble surfactants and the physical properties given from (CHIMEC S.P.A, Italy) Company, are given in Table 3. 
Table 3. Physical properties of chimec 2439.

\begin{tabular}{ccccc}
\hline Appearance & Sp. Gr. at $20^{\circ} \mathrm{C}$ & Viscosity at $20^{\circ} \mathrm{C} / \mathrm{cp}$ & Pour point $/{ }^{\circ} \mathrm{C}$ & Flash Point $/{ }^{\circ} \mathrm{C}$ \\
\hline Brown liquid & $0.94 \pm 0.02$ & $<50$ & $<-30$ & $>62$ \\
\hline
\end{tabular}

\subsection{Experimental Procedure}

\section{Emulsion Preparation}

In this research, the brine solution was used in preparing the emulsion system. The brine solution was prepared by dissolving $3 \mathrm{gm} \mathrm{NaCl}$ in $100 \mathrm{ml}$ water in order to obtain the required salinity similar to crude oil field. The emulsion was prepared by adding water, $30 \%$ vol. ( $3 \% \mathrm{wt}$. $\mathrm{NaCl})$ to the crude oil at room temperature. The emulsification was carried out by using a mixer at a speed of 5000 rpm for 60 minutes to get a stable emulsion. The de-emulsifiers were tested by using bottle test method [15]. The purpose of this testing process is to test the effectiveness of de-emulsifiers in breaking crude oil. The following procedure was followed: 1) Four beakers (100 ml) filled with the (W/O) emulsion samples, de-emulsifier or chemical compound was added in different concentrations (10 80) ppm to the contents of the beakers. b) A series of four condensers as shown in Figure 1 were joined with water bath. The water was pumped from the reservoir tank at $65^{\circ} \mathrm{C}$ into condensers, at the same time the contents of the beakers were added to the condensers to separate water from crude oil emulsion at different time intervals such as $(5,10,15,30,60,90$ and 120) minutes.

In this set of experiments, the effect of methanol and ethanol concentrations added to RP6000 and Chimec 2439 was investigated. The concentrations studied for both Methanol and Ethanol were (25\%,50\%, 75\%, and 100\%), where $M=4: 1$ Methanol to water ratio. $\mathrm{E}=4: 1 \mathrm{Ethanol}$ to water ratio.

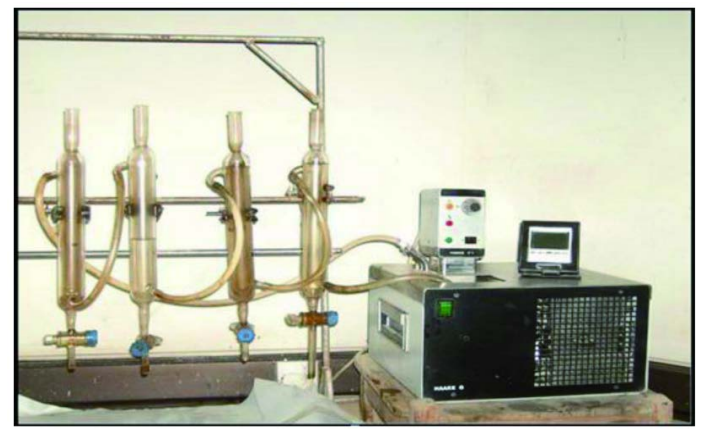

Figure 1. Water separation equipment.

\section{Results and Discussion}

\section{Effect of Alcohols on Water Separation Efficiency}

The effect of adding alcohols on water separation efficiency was carried out by using two types of alcohols methanol and ethanol, where $M=4: 1$ (methanol to water ratio), and $\mathrm{E}=4: 1$ (ethanol to water ratio) were used as a modifier agent to enhance the performance of de-emulsifiers. During the laboratory measurements, it was observed that the solubility of alcohol with water is greater in 
emulsion compared with solubility of alcohol without water. Figure 2 was obtained from Table 4 and Table 5 that shows the comparison between methanol and ethanol effect using RP6000 de-emulsifier on water separation efficiency. Also, Figure 3 was obtained from Table 6 and Table 7 that reflects the comparison between methanol and ethanol effect using Chimec 2439 de-emulsifier on water separation efficiency. Figure 2 and Figure 3 show the increased in water separation efficiency with decrease (methanol and ethanol) concentrations with time. Maximum separation efficiency reaches $61 \%$ and $56.6 \%$ at concentration (75\%), 20 ppm for RP6000 and Chimec 2439 de-emulsifiers in 120 minutes respectively. Methanol is a short chain alcohol that is very soluble in water, while ethanol is a long chain alcohol that is soluble in oil. Methanol therefore, has a good ability in promoting water separation for the emulsion system compared to ethanol. These results are in agreement with the results obtained by [16].

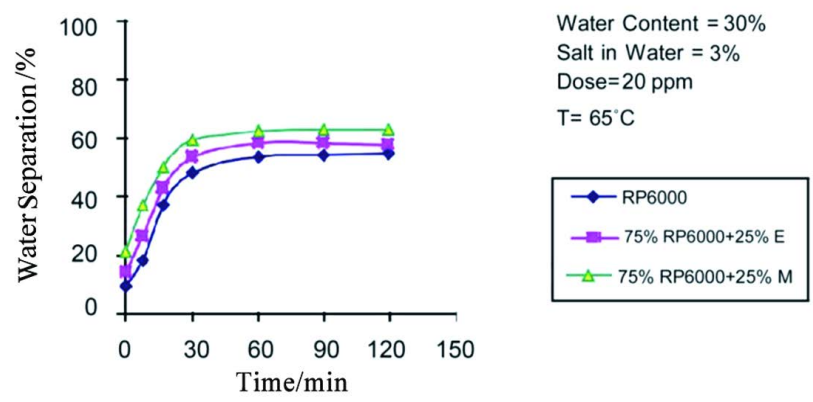

Figure 2. Comparison between methanol and ethanol effect to RP6000 on water separation efficiency.

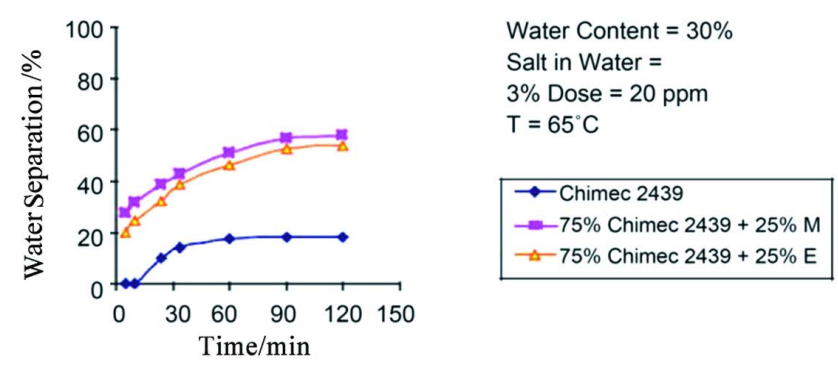

Figure 3. Comparison between methanol and ethanol effect to Chemec 2439 on water separation efficiency.

Table 4. Effect of adding Methanol to RP6000 on the separation of water from Niger Delta crude oil emulsion. RP6000 $+\mathrm{M}=0 \%+100 \%, 25 \%+75 \%, 50 \%+50 \%$ and $75 \%+$ $25 \%$, Temperature $=65^{\circ} P \mathrm{C}, P$ and water content $=30 \%$ vol. $(3 \%$ wt. $\mathrm{NaCl})$, Where $\mathrm{M}=$ 4:1 methanol to water ratio.

\begin{tabular}{cccccccc}
\hline \multirow{2}{*}{$\begin{array}{c}\text { Concentration } \\
\text { /ppm }\end{array}$} & 5 & 10 & 15 & 30 & 60 & 90 & 120 \\
\cline { 2 - 8 } & \multicolumn{7}{c}{ Separation Time/min } \\
\cline { 2 - 8 } & 10.5 & 14.3 & 18.5 & 20.5 & 34.4 & 36.7 & 36.8 \\
20 & 12.3 & 17.6 & 20.2 & 23.1 & 37.5 & 40.1 & 42.1 \\
20 & 20.7 & 21.3 & 24.6 & 40.5 & 50.3 & 53 & 54 \\
20 & 28.1 & 35.3 & 47 & 55 & 58.5 & 60.5 & 61 \\
\hline
\end{tabular}


Table 5. Effect of adding Ethanol to RP6000 on the separation of water from Niger Delta crude oil emulsion. RP6000 $+\mathrm{E}=0 \%+100 \%, 25 \%+75 \%, 50 \%+50 \%$ and $75 \%+25 \%$, Temperature $=65^{\circ} P C, P$ and water content $=30 \%$ vol. $(3 \%$ wt. $\mathrm{NaCl}$ ), Where $\mathrm{E}=4$ : lethanol to water ratio.

\begin{tabular}{cccccccc}
\hline & \multicolumn{7}{c}{ Separation Time/min } \\
\cline { 2 - 7 } $\begin{array}{c}\text { Concentration } \\
\text { /ppm }\end{array}$ & 5 & 10 & 15 & 30 & 60 & 90 & 120 \\
\cline { 2 - 7 } & \multicolumn{7}{c}{ Water Separation/\% } \\
\hline 20 & 12.4 & 12.5 & 17.5 & 21.3 & 33 & 34.2 & 34.5 \\
20 & 10.5 & 15.3 & 20 & 22 & 36.3 & 38 & 38.5 \\
20 & 21.3 & 21.9 & 21.1 & 35.5 & 47 & 48.1 & 48.8 \\
20 & 26.1 & 33.1 & 45 & 53.5 & 58 & 58.2 & 58.2 \\
\hline
\end{tabular}

Table 6. Effect of adding Methanol to Chimec 2439 on the separation of water from Niger Delta crude oil emulsion. Chimec $2439+\mathrm{M}=0 \%+100 \%, 25 \%+75 \%, 50 \%+50 \%$ and $75 \%+25 \%$, Temperature $=65^{\circ} P C, P$ and water content $=30 \%$ vol. $(3 \%$ wt. $\mathrm{NaCl})$, Where $\mathrm{M}=4: 1$ methanol to water ratio.

\begin{tabular}{cccccccc}
\hline \multirow{2}{*}{$\begin{array}{c}\text { Concentration } \\
\text { /ppm }\end{array}$} & 5 & 10 & 15 & 30 & 60 & 90 & 120 \\
\cline { 2 - 7 } & \multicolumn{7}{c}{ Water Separation/\% } \\
\cline { 2 - 7 } & 8.3 & 10.5 & 19.5 & 22.3 & 28.9 & 30.1 & 30.5 \\
20 & 14.4 & 18.4 & 21.6 & 28.1 & 32.2 & 35.4 & 35.5 \\
20 & 21 & 25.1 & 34.1 & 38 & 40.5 & 44.9 & 45 \\
20 & 27.7 & 31.5 & 35.9 & 42.5 & 48.9 & 56.6 & 56.6 \\
\hline
\end{tabular}

Table 7. Effect of adding ethanol to Chimec 2439 on the separation of water from Niger Delta crude oil emulsion. Chimec $2439+\mathrm{E}=0 \%+100 \%, 25 \%+75 \%, 50 \%+50 \%$ and $75 \%+25 \%$, Temperature $=65^{\circ} P C, P$ and water content $=30 \%$ vol. $(3 \%$ wt. $\mathrm{NaCl}$ ), Where $\mathrm{E}=4: 1$ ethanol to water ratio.

\begin{tabular}{cccccccc}
\hline \multirow{2}{*}{$\begin{array}{c}\text { Concentration } \\
/ \text { ppm }\end{array}$} & 5 & 10 & \multicolumn{7}{c}{15} & 30 & 60 & 90 & 120 \\
\cline { 2 - 8 } & \multicolumn{7}{c}{ Water Separation/\% } \\
\cline { 2 - 8 } & 5.9 & 9.8 & 14.4 & 19.5 & 20.5 & 25.4 & 26.5 \\
20 & 10.1 & 13.5 & 18.9 & 22.1 & 28.3 & 30.1 & 30.2 \\
20 & 18.5 & 20.6 & 27.5 & 32.2 & 35.5 & 41.5 & 41.6 \\
20 & 25.5 & 30.3 & 37.3 & 41.7 & 42.2 & 54.4 & 55.9 \\
20 & & & & & & &
\end{tabular}

\section{Conclusion}

In conclusion, adding methanol and ethanol as modifiers improved the performance of de-emulsifiers. Optimum alcohol percent with de-emulsifier is $25 \%$. Methanol gave higher water separation efficiency than ethanol. Methanol has a short chain while ethanol has a long chain. Methanol is therefore, more soluble in water than ethanol.

\section{Contribution to Knowledge}

Optimum alcohol percent with de-emulsifier is established as $25 \%$ concentration and methanol is recommended during de-emulsification process because of its high water separation efficiency and its solubility in water. 


\section{Acknowledgements}

We thank the management of Federal University of Technology, Owerri, Nigeria for using their laboratory during the execution of the work.

\section{References}

[1] Lissant, K.J. (1988) Emulsification and De-Emulsification, a Historical Overview. Colloids and Surfaces, 29, 15. https://doi.org/10.1016/0166-6622(88)80168-9

[2] Bhardwaj, A. and Hartland, S. (1998) Studies on Buildup of Interfacial Film at the Crude Oil/Water Interface. Journal of Dispersion Science and Technology, 19, 465473. https://doi.org/10.1080/01932699808913189

[3] Schramm, L.L. (1992) Petroleum Emulsion. In: Schramm, L.L., Ed., Emulsions Fundamentals and Applications in the Petroleum Industry, American Chemical Society, Washington DC, 1-45.

[4] Gafonova, O.V. (2000) Role of Asphaltenes and Resins in the Stabilization of Water-in-Hydrocarbon Emulsions. MSc Thesis, University of Calgary.

[5] Grace, R. (1992) Commercial Emulsion Breaking. In: Schramm, L.L., Ed., Emulsions Fundamentals and Applications in Petroleum Industry, American Chemical Society, Washington DC, 313-338. https://doi.org/10.1021/ba-1992-0231.ch009

[6] Selvarajan, R., Anantha, S.S. and Robert, A.M. (2001) Aqueous Dispersion of an Oil Soluble De-Emulsifier for Breaking Crude Oil Emulsions. US Patent No. 6294093.

[7] Staiss, F., Bohm, R. and Kupfer, R. (1991) Improved De-Emulsifier Chemistry: A Novel Approach in the Dehydration of Crude Oil, SPE Production Eng., 334-338. https://doi.org/10.2118/18481-PA

[8] NRT Science \& Technology Committee (1997) Emulsion Breakers and Inhibitors for Treating Oil Spills. Fact Sheet.

[9] Bhattacharyya, B.R. (1992) Water Soluble Polymer as Water-in-Oil De-Emulsifiers. US Patent 5100582.

[10] Ese, M.H., Galet, L., Clausse, D. and Sjoblom, J. (2006) Properties of Langmuir Surface and Interfacial Films Built up by Asphaltenes and Resins: Influence of Chemical De-Emulsifiers. Journal of Colloid and Interface Science, 220, 293-301. https://doi.org/10.1006/jcis.1999.6549

[11] Aske, N. (2002) Characterization of Crude Oil Components, Asphaltene Aggregation and Emulsion Stability by Means of near Infrared Spectroscopy and Multivariate Analysis. Ph.D. Thesis, Norwegian University of Science and Technology, Trondheim.

[12] Krawczyk, M.A. (1990) Mechanisms of De-Emulsification. Ph.D. Thesis, Institute of Technology.

[13] Dodd, H.V. (1954) The Resolution of Petroleum Emulsions. Chem. Met. Eng., 28, 249-253.

[14] Hanapi, B.M. (2006) Study on De-Emulsifier Formulation for Treating Malaysian Crude Oil Emulsion. MSc Thesis, University Technology Malaysia, Johor Bahru.

[15] Lissant, K.J. (1983) De-Emulsification Industrial Application. Marcel Dekker, New York.

[16] Bulatovic, S.M. (2007) Handbook of Flotation Reagents. Elsevier Science \& Technology Books, Amsterdam. 
Submit or recommend next manuscript to SCIRP and we will provide best service for you:

Accepting pre-submission inquiries through Email, Facebook, LinkedIn, Twitter, etc. A wide selection of journals (inclusive of 9 subjects, more than 200 journals)

Providing 24-hour high-quality service

User-friendly online submission system

Fair and swift peer-review system

Efficient typesetting and proofreading procedure

Display of the result of downloads and visits, as well as the number of cited articles Maximum dissemination of your research work

Submit your manuscript at: http://papersubmission.scirp.org/

Or contact ojogas@scirp.org 